\title{
A STUDY ON CYCLISTS BEHAVIOUR AND BICYCLES KINEMATIC
}

\author{
ALFONSO MICUCCI ${ }^{1} \&$ MAURIZIO SANGERMANO ${ }^{2}$ \\ DICAM, University of Bologna, Italy
}

\begin{abstract}
A study on cyclists' behaviour and bicycle kinematic was conducted to determine the behavioural characteristics and kinetic representatives, as they are closely linked. The study focused on the behaviour of cyclists at road intersections and on cycle paths, including the crossing speeds, the accelerations, the time spent covering a fixed distance, as well as the most complex and dynamic part of the road transport system, the human factor. Whether the road users follow the laws of traffic and adopt a cautious and considerate driving attitude has a great impact on road safety. Video cameras placed at different locations were used to collect traffic data. A post processing phase to analyze the data followed. Interesting groups behaviour of cyclists were identified, as well as many characteristics curves related to the kinematic parameters. In general, a poor attitude towards compliance with behavioural rules has emerged in the medium-sized city of Bologna, Italy, especially for male cyclists.

In addition, the average flow speed was observed under normal conditions, resulting in the order of $4 \mathrm{~m} / \mathrm{s}$. The results obtained are useful for understanding the performance of mixed traffic at intersection and on bicycle lanes, as well as building a basis for road accident reconstruction.

Keywords: safety \& hazards, traffic engineering, cyclists' behaviour, bicycle kinematic, traffic accident reconstruction, crash analysis.
\end{abstract}

\section{INTRODUCTION}

For society cycling offers many interesting advantages over other transport modes. In urban areas, cycling could be faster than the other forms of transportation and allow cyclists to avoid traffic queues. The benefits of cycling include environmental sustainability, reasonably priced infrastructures and improvements for health.

For these reasons, there is an uptrend in bicycle use and flows. For example, in the last 5 years in Bologna, there has been a $39 \%$ increase in bicycle commuting. The main effect of the increasing number of this type of mode of transport is the frequency of accidents on the roads, due to the higher exposure levels. Measures need to be proactively planned to minimize these harmful events. Therefore, there is a profound interest in studying the bicycle kinematic as well as the position of the cyclist to respect norms.

This chapter aims to provide an overview of the existing literature on bicycle use and the kinematic associated with this type of vehicle. The focus is mainly on experimental results from the field of travel behaviour, psychology and transportation design. In this paper, we have chosen to focus on cycling for several reasons. Cycling is an important aspect of travel behaviour for the society because it could add to economic wealth and, on the other hand, alleviate both traffic congestion and environmental pollution.

If researching an individual choice of cycling or using other modes of transport [1], the distance between the origin and the destination point is almost always taken into account.

Most of the times, the greater the distance, the higher the effort and the time to travel. Consequently, there is a reduction in the cycling share and in the frequency. In fact, when the trip distance increases, the cycling share is much lower [2,3]. Moreover, it might exist a maximum distance that individuals could accept to travel. Garrard et al. [4] discovered that

${ }^{1}$ Orcid:https://orcid.org/0000-0001-8662-8250

${ }^{2}$ Orcid:https://orcid.org/0000-0002-5127-4701 
women cycle shorter distances than men, with Howard McDonald and Burns **[5] suggesting $6.6 \mathrm{~km}$ for women compared to $11.6 \mathrm{~km}$ for men.

Another factor that influence the use of bicycles is the city size. Small and medium cities, like Bologna, are characterized by the highest bicycle share, probably due to the closeness between the destinations. The road design and of the cycle paths could influence cycling. Southworth [6] defined a denser city as more suitable for bicycles, because of the distances between destinations being shorter.

Another aspect to be mentioned is the infrastructure. There exist multiple bicycle infrastructures: bicycle paths, bicycle lanes and traditional streets, with or without markings. Usually, having separate bicycles lanes is expected to be safer, so cyclists can choose the relative facilities as preferential. Research confirms these statements [7,8]. Furthermore, inexperienced cyclists, women and younger cyclists are inclined to favour bicycle facilities and set them as more important [4]. Experienced cyclists do not consider bicycle path preferable to wide curb lanes. Bicycle facilities are strictly related to safety, which can be considered another factor that contributes to the use of bicycles. Continuity of bicycle infrastructure is also relevant, because the absence of a portion of it may deter some users. Pucher and Buehler [2] point out that having more bicycle paths lead to a higher bicycle share. As Dill and Voros [9] reported people said they would cycle more often if they had bicycle paths and if these were easily accessible and well-integrated in the urban context.

Stop signs, traffic lights and other traffic controlling systems are essential for traffic regulation but can also be perceived as disutility. In fact, stopping and accelerating cost cyclists a fair amount of effort. Therefore, cyclists tend to avoid traffic lights and stop signs as revealed by Stinson and Bhat [10] and by Rupi and Schweizer [11]. Experienced cyclists tend to perceive stop signs more negatively than inexpert cyclists. The reason is related to the fact that experienced cyclists feel confident and safer blending in with traffic and find travel time more important.

Bernardi et al. [12] examined the impact of other modes of transport on cyclists, resulting in a considerable decrease in the travelling speed in the mixed traffic scenario, up to $40 \%$. Micucci et al. [13] and Bardi et al. [14] are useful in locating the cyclist mobility in a more general context of urban mobility.

Cyclist's behaviour is also associated with socio-economic factors. Mode choice studies performed by Cervero [15], Räsänen and Summala [16], Stinson and Bhat [17] have shown a strong relationship among mode choice behaviour, gender and age. One of the results is that men cycle more than women.

Transportation costs affect mode choice. Cycling is relatively cheap, and this could be identified as one of the reasons to cycle. Perceived social norms are key factors affecting decision-making. Social norms can be defined as norms held by a society which influence and regulate behaviour, operating as informal social controls. Individuals can also conform their behaviour to a norm, to fit in with a group.

Safety is often revealed as the reason to avoid cycling, as mentioned above. There are two types of safety: objective and subjective. Objective safety is 'real' safety for cyclists, measured in terms of the number of bicycle incidents per million inhabitants. Subjective safety refers to how individuals perceive safety and is mostly measured in terms of the stated safety experience of the users. Klobucar and Fricker [18] claim that subjective safety levels are higher when dedicated bicycle paths and lanes are present. Petritsch et al. [19] performed research into the matter of objective cycling safety. They find that at road intersections, bicycle side paths should either be close to roadways, or the travelling speed should be reduced 
to increase the likelihood of car drivers detecting cyclists. Car parking facilities can lead to more dangerous situations for cyclists, because car drivers need to cross bicycle facilities to park. Stinson and Bhat [10] suggest that cyclists give a higher rate to roads without parking and identify them as safer than roads with adjacent parking. Pucher and Buehler [2] stated that if there is an amplified risk of having an accident, then people will tend to cycle less. Shankwiler [20] noticed that people remember what they perceive to be the dangerous portion of the route, better than typical route segments. It must be said, however, that not all people have comparable perceptions of safety. The most important result is that all the people surveyed thought that cycling was less safe than walking, driving a car or using public transport. On the other hand, cyclists gave the highest rating for bicycle safety.

Multiple bicycle-vehicle interaction studies exist, particularly on intersection areas. Bai et al. [21] assessed the behaviours of cyclists at signalized intersections through the approach of traffic conflicts. They discovered that approximately $78 \%$ of conflicts were produced by the dangerous conduct of the car drivers, which did not yield the right of way to bicycles. Cherry et al. [22] studied some practical and cost-effective measures to decrease the amount of conflicts at intersections between bicycles on bike lanes and right-turning vehicles. They suggested to redesign both the signal phase and the road geometry. An automatic safety diagnostic strategy was created by Sayed et al. [23] to estimate vehicle-bicycles conflicts at intersections using video analysis. These conflicts were effectively recognized and examined by their approach, as well as, merging conflicts. Klassen et al. [24] evaluated the factors contributing to the serious bicycle-vehicle collisions at intersections. Results showed that major variables influencing the intersection accident severity included the presence of partial crossings and bicycle signs, as well as, the cyclist's gender and age. Li et al. [25] noted that the flow of vehicles is a significant factor influencing the perception of comfort by cyclists on road bicycle lanes and exclusive path. Bella and Silvestri [26] estimated car drivers and cyclists interaction on rural roads and assessed the impacts of cross-sections and the geometric components.

This research leads to a better understanding of cyclist's behaviour in relation to the inappropriate actions in the areas of conflict with other traffic modes. The results will also be important and valuable for urban transportation policies. Another aspect studied is the kinematic of the bicycle, which offers characteristic curves (e.g. acceleration against time) useful to road accidents reconstructionist. Unfortunately, no papers related to this aspect, as we intended, has been found.

In the following chapters, the study methods are explained, as well as the results achieved.

\section{MAIN OBJECTIVE AND OBSERVATIONS}

\subsection{Main objective}

The results of the literature review have shown a profound relation between behaviour and bicycle use and mode choice. To researcher who want to plan safety or reconstruct road accidents, this aspect is particularly important, so it is worth to perform multiple observations to recognize trends and patterns. This study is not focused only on the behaviours, positions and habits of cyclists, but also on kinematics. The aim of the latter part is to obtain acceleration, speed and time characteristic curves for the average cyclist. For this purpose, different scenarios have been exanimated: high and low interference between bicycles and other modes of transport, in case of on speed crossing and starting from a halt. The macro scenario of 
high interference is associated of cyclists crossing an intersection. The macro scenario of low interference is associated of cyclists riding on a cycle path.

2.2 Analysis methodology and in-situ observations.

To achieve the above indicated goals, many observations in multiple locations have been gathered, as well as, videos showing cycling traffic scenes. Then, the analysis of the data was made for different traffic scenarios and locations, followed by the results discussion.

\section{- Behaviour}

In order to analyze the cyclists' behaviour and the stance to respect norms, multiple data have been gathered in four locations, by members of the University of Bologna: one intersection, one mixed cycle-pedestrian crossing and the other two on cycle paths. The gathering phase has been performed filling out a table, beforehand prepared, and observing the number as

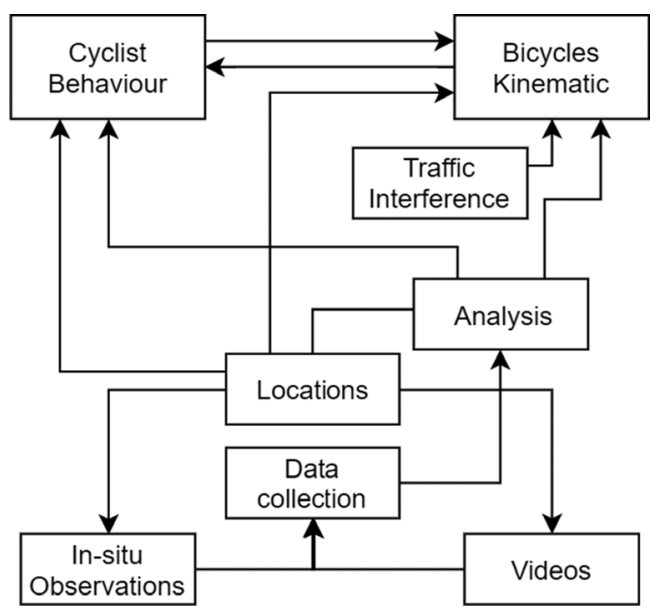

Figure 1: Assessment strategy.

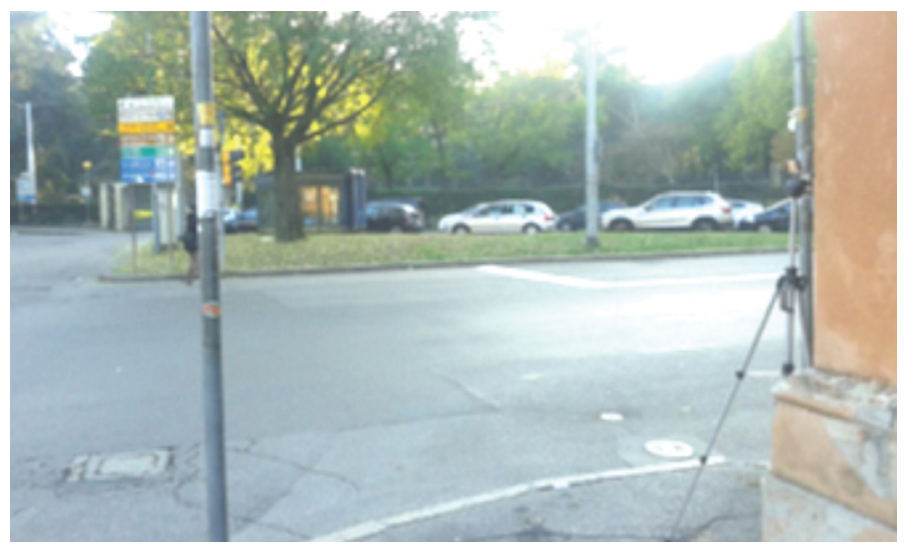

Figure 2: Position of the camera on the corner of via Saragozza. 
well as the characteristics of the cyclists passing through the different location, using both the eye-view counting and the video analysis.

It should be noted that various types of bicycles have been initially planned to be gathered (i.e. city bike, road bike, mountain bike and electric bike), as the different mechanical characteristics could lead to different kinematic behaviour. Nevertheless, the observations were limited only to city bikes, as in the city of Bologna the size of the sample related to the other types was not sufficiently large.

- Kinematic analysis

The main objective of this test is to provide a space-time graph that can provide characteristic curves for each type of cyclist. The observations were divided into two macro scenarios: high and low interference with other types of transport. Each scenario has been divided into two other sub-scenarios: bicycle starting from a halt and on speed bicycle.

The monitoring of the flows was made by video shooting, conducted with a GoPro Hero $3+$ Silver Edition camera. The high resolution and high frame rate shots $(1,080 \mathrm{p} / 60 \mathrm{fps}$, $960 \mathrm{p} / 60 \mathrm{fps}$ and $720 \mathrm{p} / 120 \mathrm{fps}$ ) were examined in laboratory after the observations were performed, using computer applications that allow to scroll the movie frame by frame and, consequently, to determine the time required to cover the distance between two known spatial points.

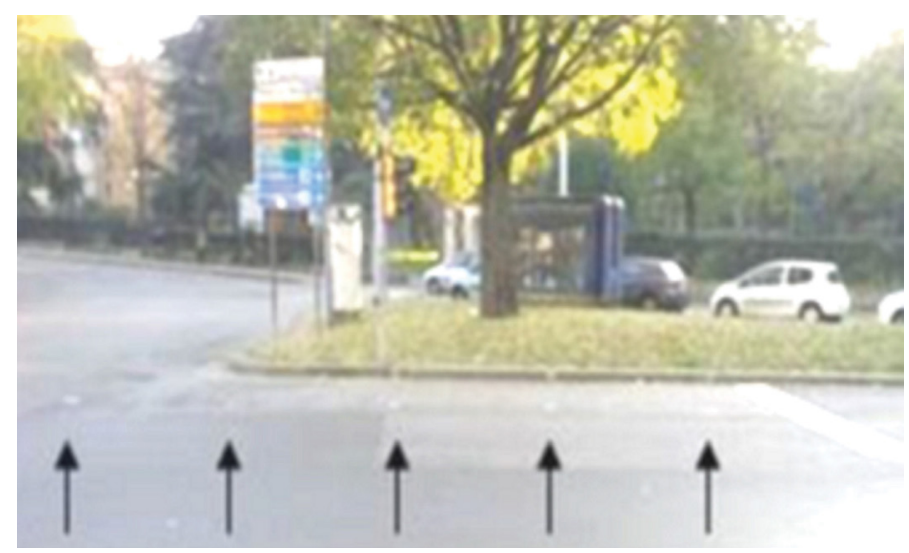

Figure 3: Reference points utilized for the visual method.

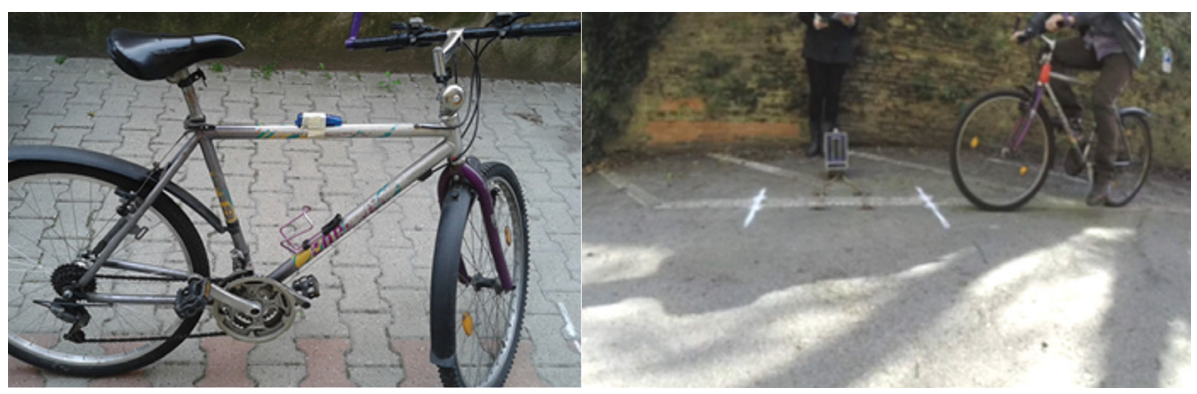

Figure 4: The upper figure shows the bicycle used for the validation with the accelerometer attached to the frame. The bottom figure shows the comparison between the pneumatic tube method and the visual method. 
The latter consisted of detection points, usually drawn on the pavement with chalk and in some cases applied using self-adhesive white plastic discs, removed at the end of the day. The position of these points was in correspondence with the distances $0,1,3,5,7,9 \mathrm{~m}$.

Starting from time, it was possible to first derive the speed, then the acceleration.

This technique has been validated by comparing the results with Apollo pneumatic tube detector, with tubes positioned on the ground at a relative distance of $0.25 \mathrm{~m}$, while the two points of reference (i.e. white stripes), needed for detection by camera, have been placed at a distance equal to $1 \mathrm{~m}$. The relevant observations were conducted using a single bicycle, such as the mountain bike shown in Figure 4.

Comparing the findings with the two different techniques, there is a good convergence of the results, with deviations not greater than $5 \%$ (see Table 1).

\subsection{Domain and size of the sample examined}

Considering the case study illustrated in the previous paragraph, it was considered of interest for the analysts to examine the behaviour of cyclists in general terms, that is, of attitude towards compliance with the Road Code standards, in kinematic terms, and in terms of cyclist's detection. The surveys were conducted in two macro-scenarios: interaction with other transport modes that require additional attention compared to normal situation, as well as with flows mostly unperturbed (e.g. cycle path travelling). In the first macro-scenario, the three crossing movements of the intersection between via Saragozza and viale Carlo Pepoli were considered: going straight, as well as turning to the right and turning to the left, and the movement of crossing the carriageway on a special cycle-pedestrian passage (i.e. cycle path). Considering the average size of urban areas, it was limited to follow the motion during the first $9 \mathrm{~m}$ of movement, with linear or curvilinear trajectory. All the observations were conducted in urban areas with higher bicycle flows, as a result of a quantitative monitoring campaign conducted by the University of Bologna in 2010-2011 for the Municipality, with Apollo pneumatic tube detector [27].

- The intersection between via Saragozza and viale Carlo Pepoli - viale Antonio Aldini, in which a transit of 131 cyclists was detected in a hour;

- Viale Giambattista Ercolani, both in correspondence of the mixed cycle-pedestrian crossing in which a transit of 76 cyclists was detected in a hour, and in correspondence with the cycle path, in which a transit of 70 cyclists was detected;

- Via Giuseppe Mazzini, in which a transit of 83 cyclists was detected in a hour, both with city centre direction (with no vehicles parked at the side of the carriageway), and with suburban area direction (with vehicles parked at the side of the carriageway);

- Via Augusto Murri in which a transit of 103 cyclists was detected in a hour.

The total number of cyclists detected was 463 (58\% men, $42 \%$ women).

Table 1: Validation technique

\begin{tabular}{cc|c}
\hline V. Centurion & V. Camera+fps & Variation In \% \\
\hline 7.16 & 7.2 & 0.5 \\
8.72 & 8.31 & 4.68 \\
15.35 & 15.43 & 0.5 \\
21.85 & 21.6 & 1.17 \\
26.01 & 27 & 3.79 \\
30.54 & 30.86 & 1.05 \\
\hline
\end{tabular}




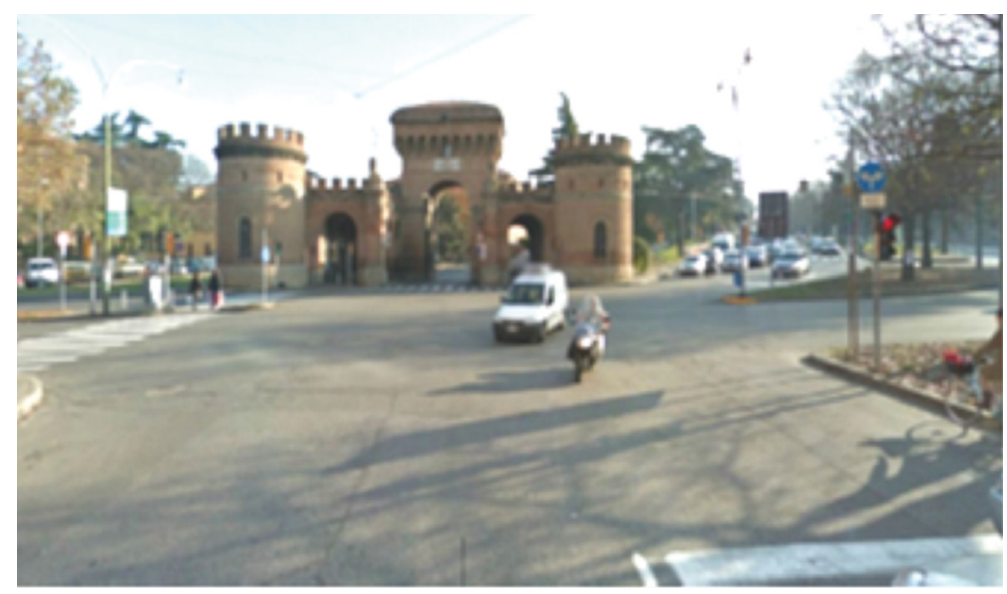

Figure 5: Intersection via Saragozza/viale Carlo Pepoli (left-hand side) - viale Antonio Aldini (right-hand side).

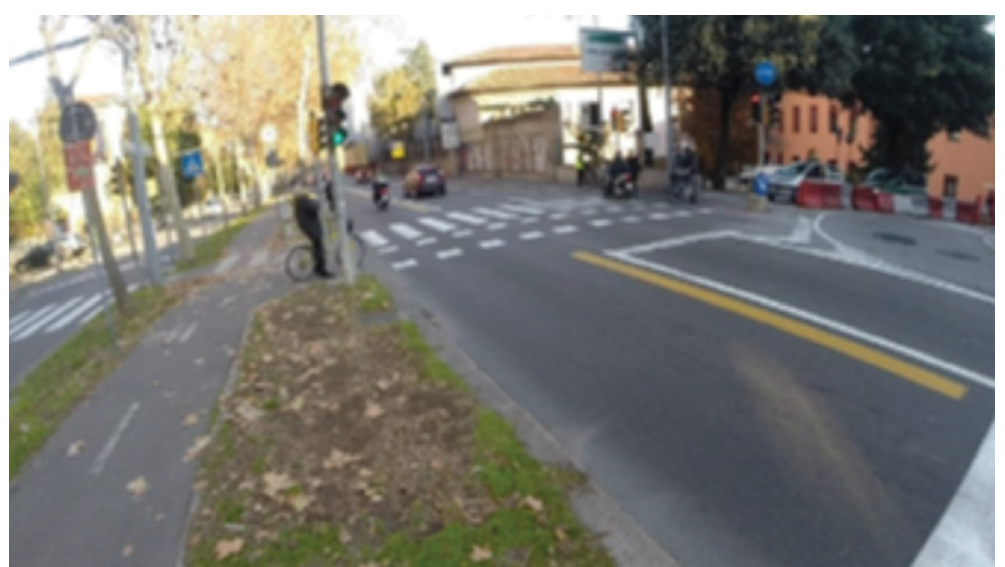

Figure 6: Zebra crossing and elephant street markings on viale Giambattista Ercolani.

\section{ANALYSIS OF THE DATA}

First, the compliance with behavioural norms is determined, in different locations and situations. Then, the focus is on the bicycle's kinematic, analysing multiple locations and scenarios.

\subsection{Respect of behavioural norms}

Table 2 shows the results obtained. As can be seen, a big majority, particularly men, assumed an irregular behaviour, which consists of:

- crossing with a red-light signal, as mentioned by Fraboni et al [28];

- irregular trajectory: cyclists used a questionable trajectory on the street, which could be deemed as unsafe; 
Table 2: Results of the test phase.

\begin{tabular}{|c|c|c|c|c|c|}
\hline Observation sites & Behaviour & $\%$ & Type of Violation & Men [\%] & Women [\%] \\
\hline \multirow[t]{6}{*}{ Intersection's area } & Well behaved & 43 & - & 34 & 56 \\
\hline & & & Red Light Jumping & 42 & 43 \\
\hline & Wrongly & & Irregular Trajectory & 37 & 47 \\
\hline & behaved & & Wrong Direction & 17 & 10 \\
\hline & & & Others & 4 & 0 \\
\hline & & 57 & - & 66 & 44 \\
\hline \multirow{4}{*}{$\begin{array}{l}\text { On cycle crossing } \\
\text { on bicycle path }\end{array}$} & Well behaved & 64 & - & 45 & 76 \\
\hline & Wrongly & & Red Light Jumping & 76 & 100 \\
\hline & behaved & & Driving One-handed & 24 & 0 \\
\hline & & 36 & - & 55 & 24 \\
\hline
\end{tabular}

- wrong direction on the street: cyclist travelled in opposite direction;

- violations of low occurrence, including driving during a telephone call, as well as the transportation of oversized loads or tilting loads.

Furthermore, it should be noted that only $4 \%$ of all observed cyclists were wearing the helmet, because in Italy is not mandatory.

\subsection{Bicycle's kinematic}

The main objective of this section of the study is to provide a space-time graph that defines the motion of an average cyclist in different situations.

The scenarios that were analyzed are:

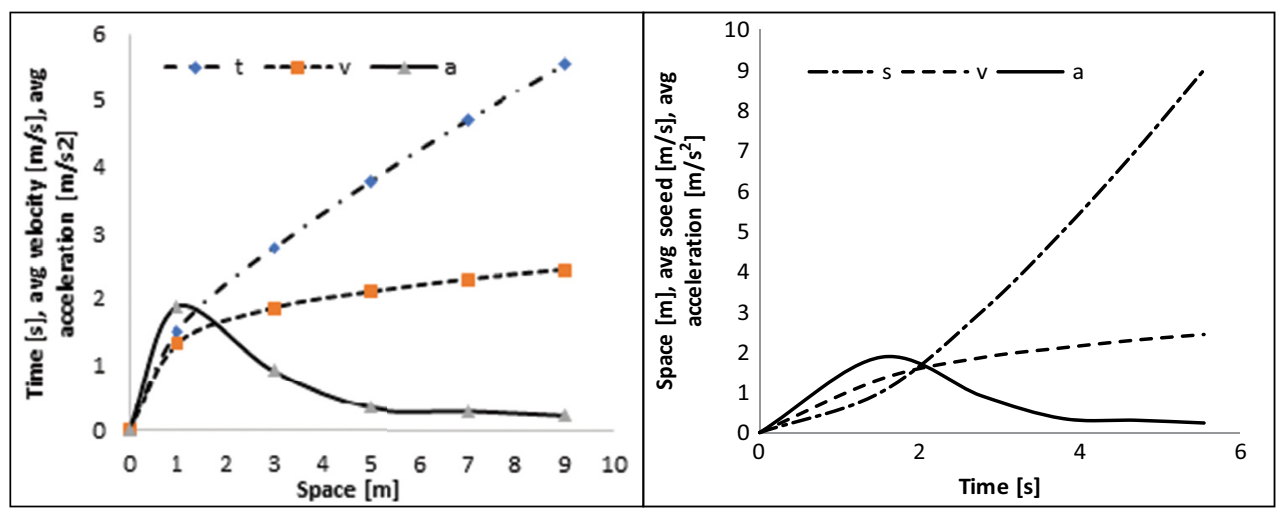

Figure 7: Kinematics in crossing straight starting from a halt at an intersection. 


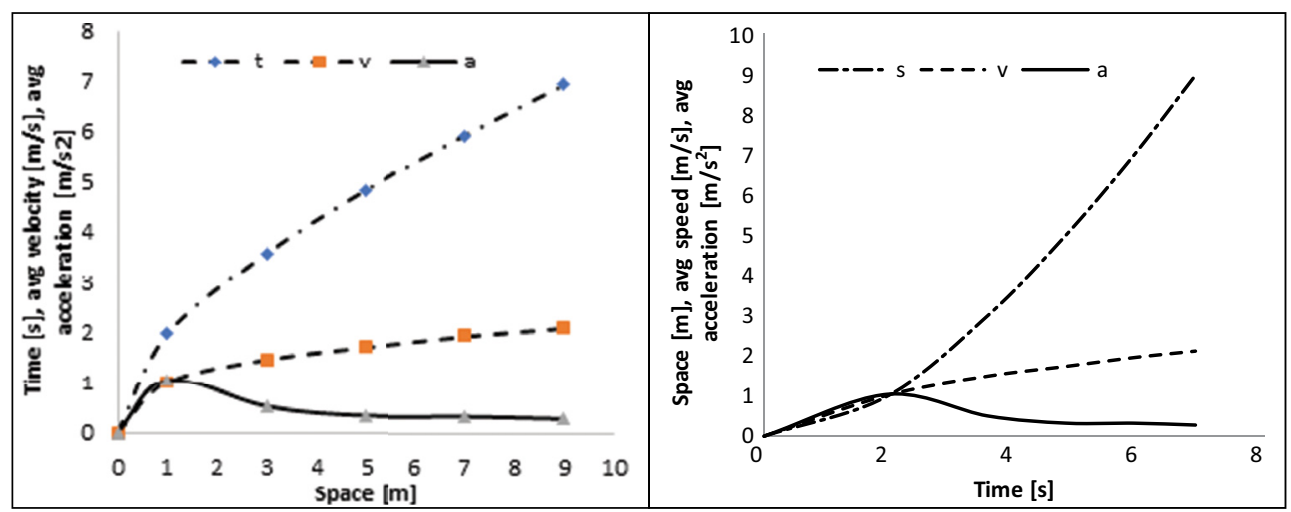

Figure 8: Kinematics in left turn, starting from a halt at an intersection.

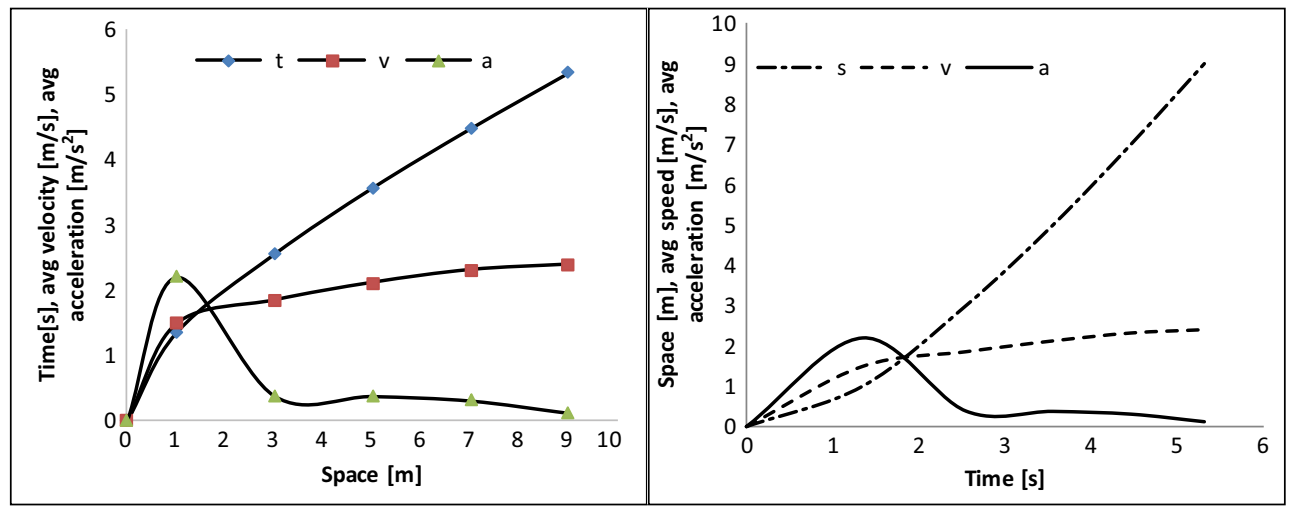

Figure 9: Kinematics in right turn, starting from a halt from an intersection.

1) macro scenario of high interference with other mode of transport (i.e. the cyclists were riding through an intersection or a bicycle crossing). The scenarios for turning left, right and crossing were examined;

2) macro scenario of low interference with other mode of transport (i.e. the cyclists were travelling on the side of the street or on a reserved lane).

In each of these sub-scenarios were considered: starting from a halt and on speed cycling.

The graphs shown are very useful for security planning and for the reconstruction of an accident involving a bicycle. For example, given the width of a cycle path, or of a carriageway, from the graphs it is possible to directly estimate the time required for crossing and evaluate the minimum duration of the traffic light green. Moreover, knowing the distance of the impact from the starting of the intersection, it is possible to estimate the time taken by the cyclist to reach that point. 


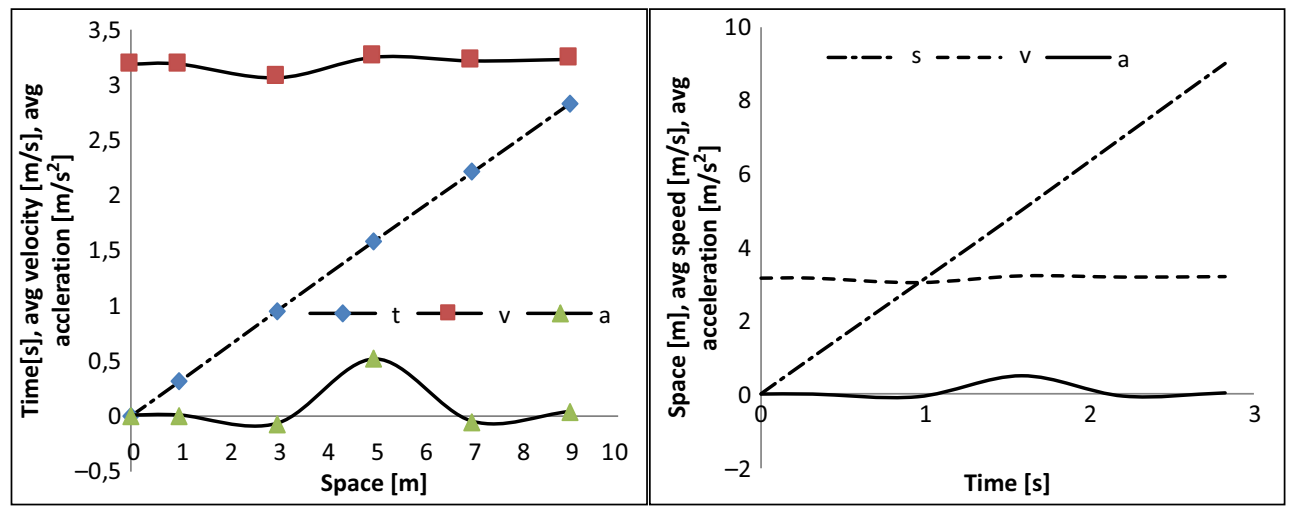

Figure 10: Kinematics in straight on speed crossing at an intersection.

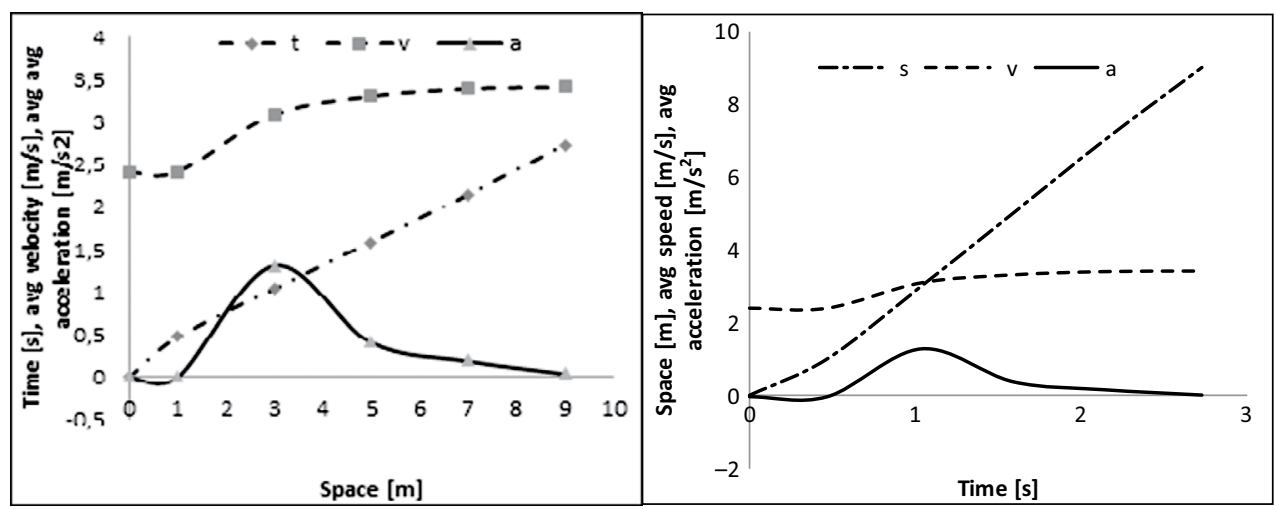

Figure 11: Kinematics in left turn on speed at an intersection.

In this regard, in the first analysis, the study on the motion of cyclists based on age, gender and type of pedalling (light, medium and demanding) was evaluated. The first observations conducted, however, showed a poor correlation of the kinematic data with the type of pedal stroke. For this reason, all the graphs are referred to the average cyclist (i.e. no distinction of age and gender).

\subsubsection{Macro scenario of high interference with other modes of transport}

In this section, multiple cases are reviewed. All of them were performed in the case of high interference traffic (i.e. intersection scenario in which there is a high likelihood of vehicle interference).

a) Crossing straight starting from a halt at an intersection.

The graph in Fig. 7 shows the almost linear relationship between the space travelled by the cyclist and the time elapsed to cover the relative distance. Only the first $9 \mathrm{~m}$ travelled by the cyclist have been observed. 


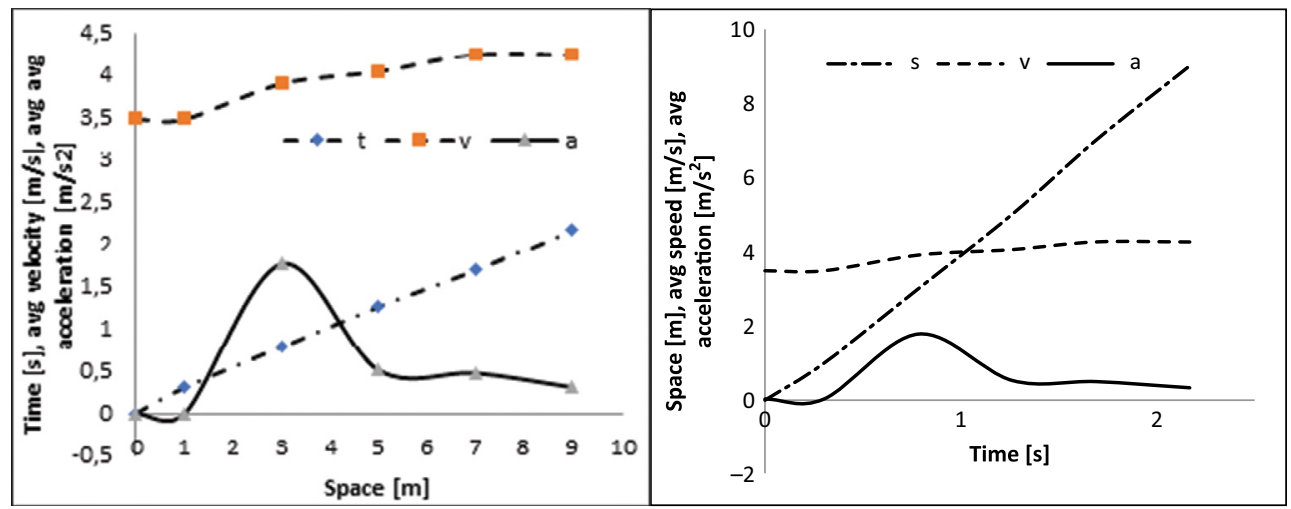

Figure 12: Kinematics in right turn on speed at an intersection.

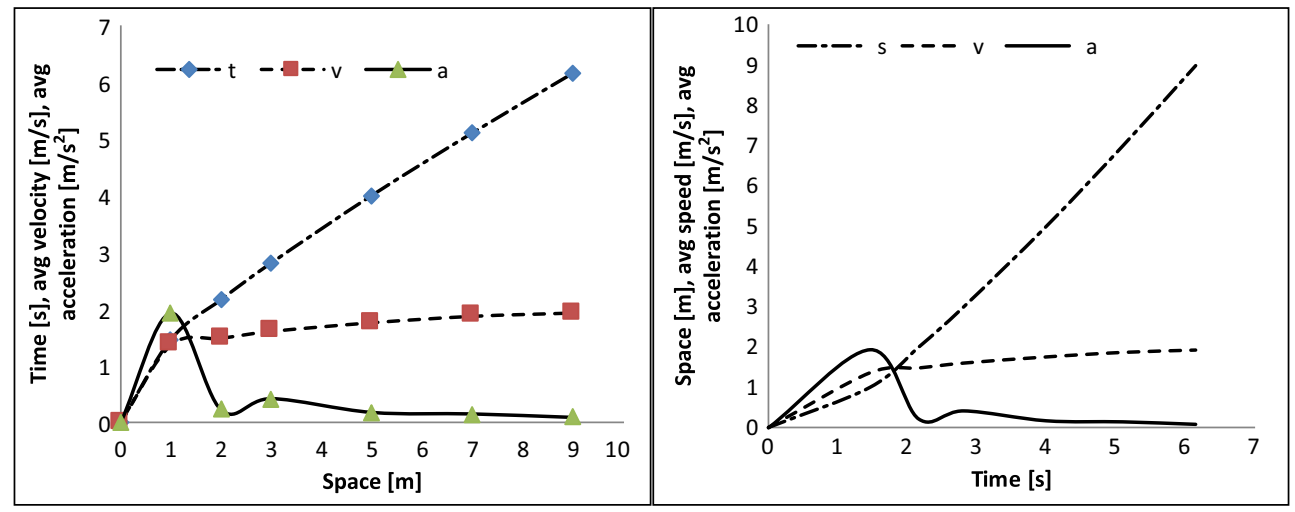

Figure 13: Kinematics in crossing on a cycle path starting from a halt.

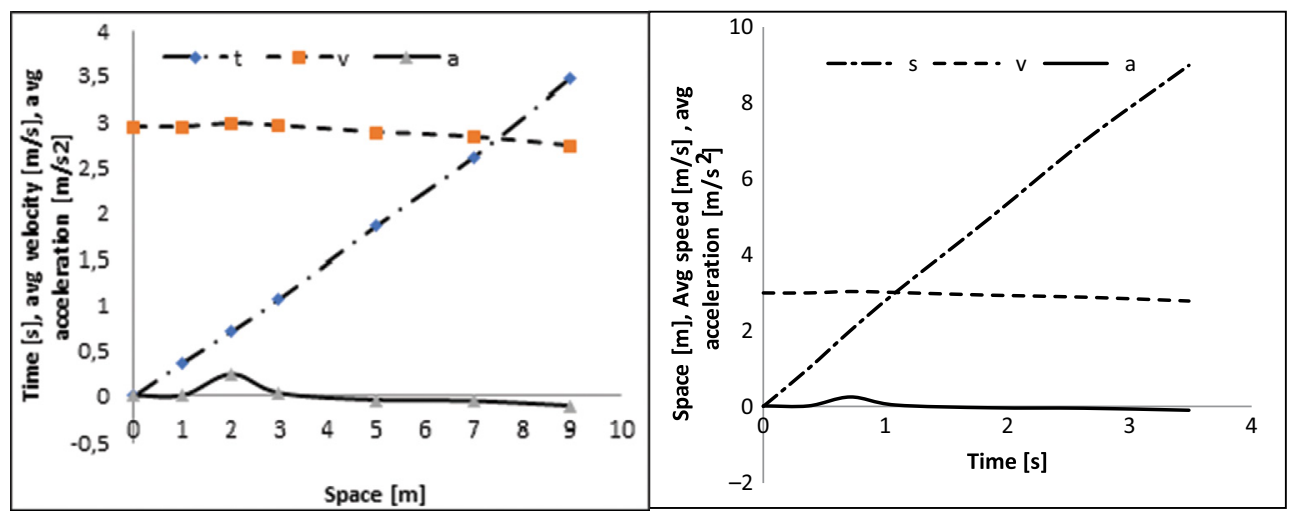

Figure 14: Kinematics in cycle crossing on a cycle path on speed. 
The time graph assumes a quasi-linear relationship with the space (t-curve). Concerning the acceleration curve (a-curve), there is a peak in the first meter travelled by the cyclist equal to about $2 \mathrm{~m} / \mathrm{s}^{2}$, and then decreasing parabolically to the minimum value of $0.25 \mathrm{~m} / \mathrm{s}^{2}$. Velocity increases with two different slopes ( $v$-curve). At the first meter the cyclist reaches a speed of $1.3 \mathrm{~m} / \mathrm{s}$ and then rises linearly at a speed of $2.4 \mathrm{~m} / \mathrm{s}$ in the $9 \mathrm{~m}$ travelled. It can be noticed that in this type of scenario (i.e. starting from a stop in high interference of traffic):

- at the $1 \mathrm{~m}$ mark, there is the peak of acceleration;

- the average cyclist reaches pretty much the cruising speed after just $2 \mathrm{~m}$.

b) Left turn, starting from a halt at an intersection.

The time graph assumes a quasi-linear relationship with the space, as before (Fig. 8). Concerning the acceleration curve, there is a peak in the first meter travelled by the cyclist equal to about $1.1 \mathrm{~m} / \mathrm{s}^{2}$, and then decreasing with a parabolic pattern to the minimum value of $0.2 \mathrm{~m} / \mathrm{s}^{2}$.

Speed increases with two different slopes. At the $1 \mathrm{~m}$ mark the cyclist reaches a speed of $1.1 \mathrm{~m} / \mathrm{s}$ and then rises linearly at a speed of $1.9 \mathrm{~m} / \mathrm{s}$ at the $9 \mathrm{~m}$ travelled. It can be noticed that in this type of scenario, the values of acceleration are considerably lower compared to the previous case, due to a curvilinear trajectory assumed by the cyclist. Likewise, the speed is lower in magnitude than before.

c) Right turn, starting from a halt from an intersection

This scenario in Fig. 9 is comparable to the one labelled with the letter 'b', but the cyclist is turning right this time. The peak of the acceleration $\left(2.2 \mathrm{~m} / \mathrm{s}^{2}\right)$ is reached after $1 \mathrm{~m}$, like in the previous cases. The value is slightly higher compared to the case ' $b$ ', since a right turn is less influenced by the other modes of transport (in Italy). The maximum average speed reached by the cyclists, in $1 \mathrm{~m}$, is slightly higher too, at $1.7 \mathrm{~m} / \mathrm{s}$.

d) Straight on speed crossing at an intersection.

In the scenario of Fig. 10, the cyclist was crossing the intersection on speed. Hence, the velocity is almost constant, at $3.25 \mathrm{~m} / \mathrm{s}$, with a small slowdown before the intersection. Regarding the acceleration, there is a spike of $0.5 \mathrm{~m} / \mathrm{s}^{2}$ at the $5 \mathrm{~m}$ mark, needed to maintain the cruising speed.

e) Left turn on speed at an intersection

This scenario is very similar to the last one, except for the fact that the cyclists were turning left at the intersection.

In this case the velocity, after a low increase in value from $2.5 \mathrm{~m} / \mathrm{s}$, assumes a constant pattern $(\sim 3.4 \mathrm{~m} / \mathrm{s})$. About the acceleration, it can be noticed a slight deceleration during the first meter. Then, a spike of $1.5 \mathrm{~m} / \mathrm{s}^{2}$ at the $3 \mathrm{~m}$ mark, with the aim of increasing the speed to the value of $3.4 \mathrm{~m} / \mathrm{s}$.

f) Right turn on speed at an intersection

This scenario in Fig. 12 is very similar to the 'e' case, except for the fact that the cyclists were turning right at the intersection.

In this case the velocity after a low increase in value, assumes a constant trend $(\sim 4.25 \mathrm{~m} / \mathrm{s})$. Regarding the acceleration, it can be noticed a low deceleration during first meter. Then, a 
spike of $1.75 \mathrm{~m} / \mathrm{s}^{2}$ at the $3 \mathrm{~m}$ mark, in order to increase the speed to the value of $4.25 \mathrm{~m} / \mathrm{s}$. In the scenarios of on speed crossing, this represents the one with the highest speed's values, as to represent the almost non-interaction with other modes of transport when turning right.

\subsubsection{Macro scenario of low interference with other modes of transport}

a) Crossing on a cycle path starting from a halt

The graph (Fig. 13) shows the almost linear relationship between the space travelled by the cyclist and the time elapsed to cover the relative distance. The time (t-curve) assumes a quasi-linear relationship with the space. Concerning the acceleration curve (a-curve), there is a peak in the first meter travelled by the cyclist equal to about $2 \mathrm{~m} / \mathrm{s}^{2}$, and then decreasing parabolically to the minimum value of $0.15 \mathrm{~m} / \mathrm{s}^{2}$, after a tiny bump at the $3 \mathrm{~m}$ mark. Speed (v-curve) increases with two different slopes. At the first meter the cyclist reaches a speed of $1.5 \mathrm{~m} / \mathrm{s}$ and then rises linearly at a speed of $1.95 \mathrm{~m} / \mathrm{s}$ in the $9 \mathrm{~m}$ travelled. It can be noticed that in this type of scenario (i.e. starting from a stop in low interference of traffic), at the $1 \mathrm{~m}$ mark, there is the peak of acceleration and the average cyclist reaches pretty much the cruising speed after just $1 \mathrm{~m}$, like has already been seen in the first three cases analyzed.

b) On cycle crossing on a cycle path on speed.

In this case the velocity is almost constant $(\sim 3 \mathrm{~m} / \mathrm{s})$. Regarding the acceleration, it can be observed a spike of $0.25 \mathrm{~m} / \mathrm{s}^{2}$ at the $2 \mathrm{~m}$ mark, in order to keep the cruising speed. The lack of interference with other type of traffic is reflected in the almost invariant values of speed and acceleration.

\section{DISCUSSION}

From the analyses performed some general trend and patterns can be identified. As part of this work, the outcomes of a comprehensive campaign to monitor the cyclist's behaviour and their kinematic have been examined in two macro-scenarios: intersection area (i.e. interaction with other mode of traffic which requires additional attention), and on cycle crossing on a bicycle path (i.e. the interaction with other modes of traffic is lower).

In general, in the city of Bologna, a poor attitude towards compliance with behavioural norms has emerged (43\% at intersection's area, 64\% while crossing in bicycle path). The most frequent infringements detected were jumping the red light and wrong way driving down the street. In the case of on speed crossing, jumping the red light could be attributed to the fact that the cyclists tend to maintain the cruising speed, as stopping is perceived as a power-hungry task. Concerning the kinematic parameters of interest for road accident reconstruction, space-time diagrams have been also defined both for an intersection and a cycle path. These curves allow, known the space travelled by the cyclist, to determine the relative time elapsed to cover it. Moreover, the general pattern is that cyclists rode at higher speed in the case of right turn at the intersection compared to left turn, as well as, going straight. Likewise, the average flow speed in normal conditions was detected, resulting in the order of $4 \mathrm{~m} / \mathrm{s}$ in intersection area and a little more in the case of travelling on cycle path, due to the less interference with other modes of transport, values in line with those reported in the literature. Furthermore, it must be noticed that, just $1 \mathrm{~m}$ is necessary for the cyclist to reach the cruising speed, starting from a halt.

The data showed above can be used to evaluate the avoidability of a cyclist being run over. For example, considering a merging manoeuvre to the left, starting from a halt on a road 
6-7 $\mathrm{m}$ wide, it appears that the average time needed to complete it is approximately $1.5 \mathrm{~s}$ (see Fig. 7); which is comparable with the psychotechnical time needed for a driver to start the reaction phase. This small interval does not allow the vehicle to be completely stopped.

Furthermore, cyclists who turn right, starting from a halt at an intersection, appear to be able to maintain a higher travel speed compared to the turning left scenario, possibly due to a lower interaction with other modes of transport.

Moreover, riding the bicycle on a cycle path seems to favour higher travelling speed and less prudence, since the greater safety perceived.

\section{CONCLUSIONS}

In conclusion, further investigations of factors and data seem warranted before drawing more accurate conclusions regarding cyclist's behaviour and bicycles kinematic (e.g. increasing the number of observations in multiple locations and using multiple bicycle types such as electric and road bikes, as well as, mountain bikes).

However, the results achieved so far can already be used to reconstruct road accidents involving bicycles and, as part of the road safety review procedure, to define policies and structures to mitigate the cyclists' risk, including infrastructures to reduce conflict points or impose a speed reduction in compliance with traffic rules, in points that cannot be removed.

\section{REFERENCES}

[1] Rietveld, P., Determinants of bicycle use: do municipal policies matter? Transportation Research Part A, 38, pp. 531-550, 2004.

[2] Pucher, J. \& Buehler, R., Why Canadians cycle more than Americans: a comparative analysis of bicycling trends and policies. Transport Policy, 13(3), pp. 265-279, 2006.

[3] Zacharias, J., Non-motorized transportation in four Shanghai districts. International Planning Studies, 10(3-4), pp. 323-340, 2005.

[4] Garrard, J., Rose, G. \& Lo, S.K., Promoting transportation cycling for women: the role of bicycle infrastructure. Preventive Medicine, 46(1), pp. 55-59, 2008.

[5] Howard McDonald, C. \& Burns, E.K, Cycling to Work in Phoenix: Route Choice, Travel Behavior, and Commuter Characteristics, Transportation Research Board: Washington, DC, 2001.

[6] Southworth, M., Designing the walkable city. Journal of Urban Planning and Development, 131(4), pp. 246-257, 2005.

[7] Taylor, D. \& Mahmassani, H., Analysis of stated preferences for intermodal bicycletransit interfaces. Transportation Research Record, 1556, pp. 86-95, 1996.

[8] Hunt, J.D. \& Abraham, J.E., Influences on bicycle use. Transportation, 34, vitettpp. 453-470, 2007.

[9] Dill, J. \& Voros, K., Factors Affecting Bicycling Demand: Initial Survey Findings from the Portland Region, Transportation Research Board: Washington, DC, 2007.

[10] Stinson, M. A. and Bhat, C. R. (2003) An Analysis of Commuter Bicyclist Route Choice Using Stated Preference Survey (Washington, DC: Transportation Research Board).

[11] Rupi, F. \& Schweizer, J., Evaluating cyclist patterns using GPS data from smartphones. IET Intelligent Transport Systems, 2018. In press. DOI: 10.1049/iet-its.2017.0285.

[12] Bernardi, S., Krizek, K.J. \& Rupi, F., Quantifying the role of disturbances and speeds on separated bicycle facilities. Journal of Transport and Land Use, 9(2), pp. 105-119, 2016. 
[13] Micucci, A., Mantecchini, L. \& Sangermano M., Analysis of the relationship between turning signal detection and motorcycle driver's characteristics on urban roads; a case study. Sensors, 19(8), p. 1802, 2019. DOI: 10.3390/s19081802.

[14] Bardi A., Mantecchini L., Grasso D., Paganelli F., Malandri C., Flexible Mobile Hub for E-Bike Sharing and Cruise Tourism: A Case Study, Sustainability 2019, 11, 5462; doi:10.3390/su11195462

[15] Cervero, R., Built environments and mode choice: toward a normative framework. Transportation Research Part D: Transport and Environment, 7(4), pp. 265-284, 2002.

[16] Räsänen, M. \& Summala, H., Attention and expectation problems in bicycle-car collisions: an in-depth study. Accident Analysis and Prevention, 30(5), pp. 657-666, 1998.

[17] Stinson, M.A. \& Bhat, C.R., A Comparison of the Route Preferences of Experienced and Inexperienced Bicycle Commuters, Transportation Research Board: Washington, DC, 2005.

[18] Klobucar, M.S. \& Fricker, J.D., A Network Evaluation Tool to Improve Real and Perceived Bicycle Safety (Transportation Research Board: Washington, DC, 2007.

[19] Petritsch, T.A., Landis, B.W., Huang, H.F. \& Challa, S., Sidepath Safety Model: Bicycle Sidepath Design Factors Affecting Crash Rates, Transportation Research Board: Washington, DC, 2006.

[20] Shankwiler, K.D., Developing a framework for behaviour assessment of bicycling commuters: a cyclist-centric approach, School of Industrial Design, p. 87, Georgia Institute of Technology: Atlanta, 2006.

[21] Bai, L., Liu, P., Chen, Y., Zhang, X., \& Wang, W., Comparative analysis of the safety effects of electric bikes at signalized intersections. Transportation Research Part D: Transport and Environment, 20, pp. 48-54, 2013.

[22] Cherry, C.R., Hill, T.Q., \& Xiong, J., Assessing countermeasures designed to reduce hazards between bike lane occupants and right-turning automobiles in China. Journal of Transportation Safety and Security, 4, pp. 277-294, 2012.

[23] Sayed, T., Zaki, M. H., \& Autey, J. Automated safety diagnosis of vehicle-bicycle interactions using computer vision analysis. Safety Science, 59, pp. 163-172, 2013.

[24] Klassen, J., El-Basyouny, K., \& Islam, M.T., Analysing the severity of bicycle-motor vehicle collision using spatial mixed logit models: a city of edmonton case study. Safety Science, 62, pp. 295-304, 2014.

[25] Li, Z., Wang, W., Liu, P. \& Ragland, D.R., Physical environments influencing bicyclists' perception of comfort on separated and on-street bicycle facilities. Transportation Research Part D: Transport and Environment, 17(3), pp. 256-261, 2012.

[26] Bella, F. \& Silvestri, M., Interaction driver-bicyclist on rural roads: effects of cross-sections and road geometric elements. Accident Analysis \& Prevention, 102, pp. 191-201, 2017.

[27] Rupi, F. et al, Monitoraggio dei flussi di biciclette sulle principali piste ciclabili del Comune di Bologna, http://www.comune.bologna.it/media/files/flussi_ciclabili_2011_ relazione_universit_bologna.pdf (accessed 27 August 2019)

[28] Fraboni F., Marín Puchades V., De Angelis M., Pietrantoni L. \& Prati G., Red-light running behavior of cyclists in Italy: an observational study. Accident Analysis and Prevention, 120, pp. 219-232, 2018. 